\title{
THERMOCHEMICAL REMANENT MAGNETIZATION IN JURASSIC SILICIC VOLCANICS FROM NEVADA,
} U.S.A.

\author{
J.W. GEISSMAN ${ }^{1}$ and R. VAN DER VOO \\ Department of Geological Sciences, University of Michigan, Ann Arbor, MI 48109 (U.S.A.)
}

Received February 1, 1980

Revised version received April 10, 1980

\begin{abstract}
Characteristic magnetizations from Middle Jurassic dacitic to andesitic subaerial volcanics (the Fulstone and Artesia Formations) in the Buckskin Mountain Range, western central Basin and Range Province, are well-grouped, generally display univectorial decays to the origin in demagnetization and have hematite blocking temperatures restricted almost entirely to above $620^{\circ} \mathrm{C}$. Petrographic, rock magnetic and electron microprobe investigations confirm that nearly pure hematite is the essential magnetic phase (up to about $10 \mathrm{vol}$. \%) occurring as a replacement of coarse titaniferous magnetite phenocrysts and fine groundmass particles, as a secondary alteration product of ferromagnesian phenocrysts and as a mobilized phase filling cracks and other open spaces. The presence of antipodal directions in each flow unit and in interbedded volcanoclastic units (some having retained magnetite as a major magnetic phase) and magnetite-dominated remanences in time-equivalent intrusives cutting the flows indicates that the volcanics acquired their hematite remanence, a faithful record of the geomagnetic field, in high-temperature, deuteric oxidation during and following their emplacement, not during a later thermal event such as regional metamorphism. The remanence is probably a thermochemical remanent magnetization, although part may be of thermoremanent origin.
\end{abstract}

\section{Introduction}

A general and often tacit assumption in paleomagnetic investigations of igneous rocks is that the essential (characteristic) remanence is a thermoremanent magnetization (TRM) residing almost entirely in a cubic, inverse spinel phase whose composition lies along or near the magnetite-ulvöspinel join (e.g. $[1,2]$ ). Other primary(?), magnetic phases, e.g. rhombohedral oxides, may be present, but unless magnetite is vastly subordinate to the latter phases, the remanence should be dominated by magnetite, by virtue of its high TRM capabilities [1,3] and the fact that the rhombohedral phases present usually have compositions of significantly lower saturation magnetization values and often Néel temperatures close to or less than room temperature. In fact, primary

\footnotetext{
1 Now at: Department of Geology, University of Toronto, Toronto, Ont. M5S 1A1, Canada.
}

magnetic mineralogies in igneous rocks are generally simple, the essential reason being that the compositions of the spinel and/or rhombohedral phases present in a partial silicate melt are controlled by the $\mathrm{Fe}^{2+} / \mathrm{Fe}^{3+}$ ratio of the melt, in turn regulated by the melt's temperature, $f_{\mathrm{O}_{2}}$ and composition [4-6]. For a given temperature, the $f_{\mathrm{O}_{2}}$ 's of most silicate melts (as determined by direct measurements or compositions of coexisting oxides) are constrained, lying 1-2 $\log$ units below the magnetite-hematite buffer [7] and parallel to and centered on the fayalite-magnetite-quartz buffer [8], as reviewed by Haggerty [9]. The composition of the original, magmatic magnetic mineralogy in most rocks is predictable, and hematite is precluded as a magmatic phase. Subsolidus chemical alteration processes, however, may produce a complex assemblage of secondary alteration products and, if occurring below the Curie or Néel temperatures of the magnetic phases produced, lead to magnetizations which are not of TRM origin, but of ther- 


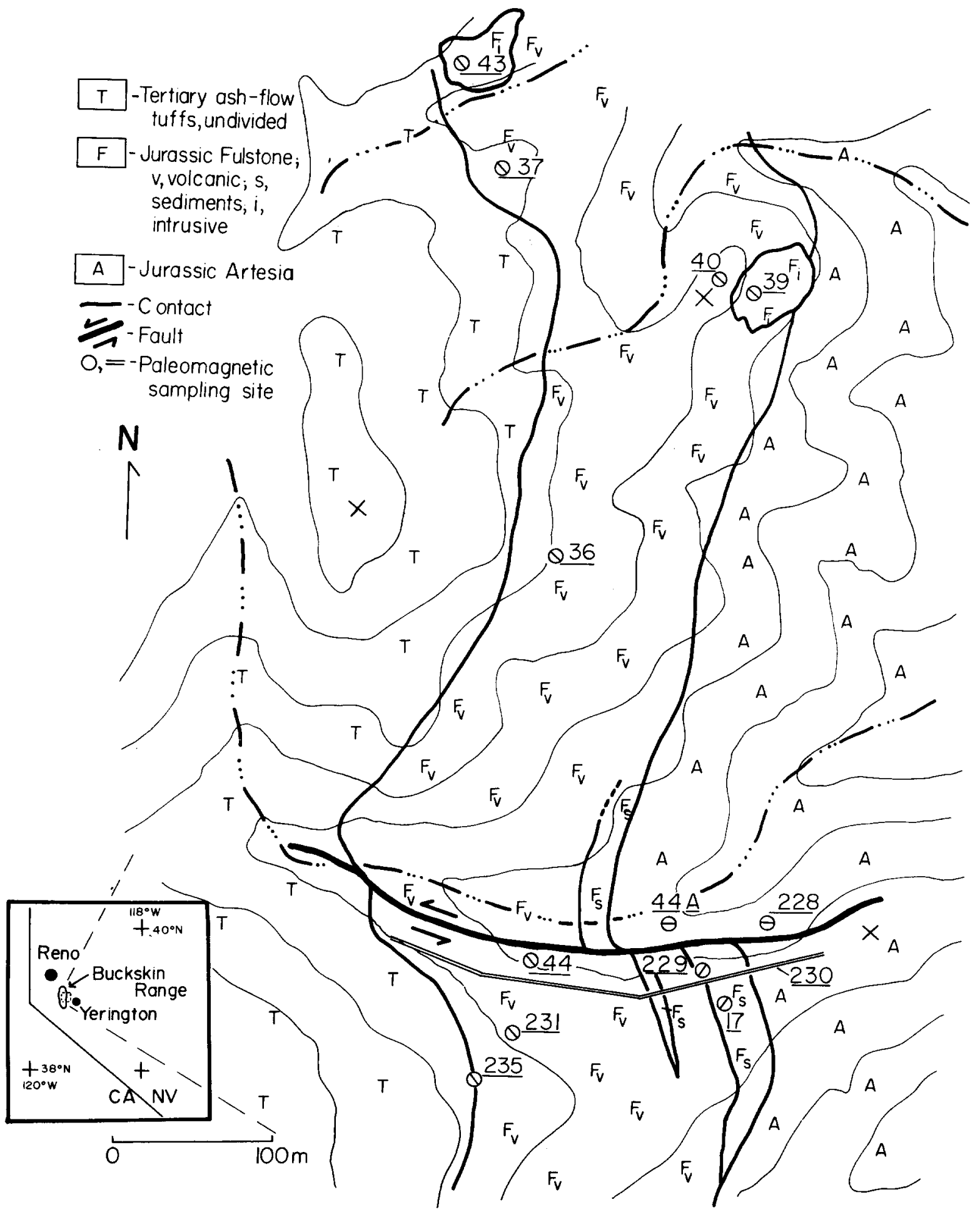

Fig. 1. Location map of the Yerington district and generalized geologic map of the sampling area in the central Buckskin Range. 
mochemical (TCRM) [10] or purely chemical (CRM) origin.

For paleomagnetic investigations, the magnetitedominated remanence determined in demagnetization procedures on igneous rocks is, though we emphasize not always, the one most closely associated with the formation of the rock, and has the greatest probability of being of TRM origin [4,11]. The purpose of this discussion is to describe and propose an origin for a remanence virtually dominated by hematite in a suite of volcanic to subvolcanic silicic flows and pyroclastics. Petrologic as well as paleomagnetic evidence suggests that the lithologies appear to have faithfully recorded the geomagnetic field, even though the magnetization is clearly not "primary" in the strictest sense of the word. We infer that the extremely stable remanence of the units, due to a magnetic phase in disequilibrium with the original magmatic magnetic phases, is penecontemporaneous with the deposition of the units.

The formations are Middle Jurassic and are from the western portion of the Yerington mining district, Nevada (Fig. 1). A paleomagnetic study [12] of Middle Mesozoic through Late Cenozoic deformation in this area has involved the examination of several lithologies, including these volcanics, the Fulstone and Artesia Formations. Paleomagnetic data from these units, extrusive equivalents or host rock and mineralizing intrusives in the district [13] and the youngest stratified lithologies of Mesozoic age in the district, are important because, if penecontemporaneous with emplacement, they may provide a more accurate evaluation of post-Middle Jurassic deformation than those from intrusive counterparts. Knowledge of the age of acquisition of their remanence is thus critical in deciphering a part of the deformational history of the district.

\section{General geology}

The Artesia and Fulstone Formations of the Yerington district are part of a general suite of Middle Mesozoic units in the western Basin and Range Province which are indicative of significant and continuous orogenic activity $[14,15]$. The regional setting of these and surrounding associated units is described elsewhere [15-17] and will not be discussed. In the
Yerington district, the predominantly andesitic Artesia Formation and quartz latitic to dacitic Fulstone Formation are stratigraphically younger than coarse terrigenous sands of the Early Jurassic Ludwig Formation [15,18], whose presence indicates the cessation of marine deposition in this part of the Cordillera. The Artesia and Fulstone Formations are best exposed in the Buckskin Range, about $5 \mathrm{~km}$ west of Yerington (Fig. 1). The overall geology of this sequence is complicated by locally intense hydrothermal alteration at the base of the Artesia sequence in the southern Buckskin Range, regional low-grade metamorphism, intrusive activity and Late Cenozoic faulting producing small, structurally distinct fault blocks. The dominant rock types of the Artesia Formation, which often exhibits a gradational contact with a granodiorite of batholithic dimensions in the district, are (1) a mafic-rich andesite-diorite, (2) a strongly altered variant of this diorite, (3) andesitic conglomerates, sandstones and other subaqueous volcanoclastic rocks, interbedded with andesitic flows and breccias, and (4) rocks composed of $90 \%$ or more quartz and originally rhyolitic volcanics. In the southern part of the range, mapping by the senior author indicates that the entire sequence may be over $1700 \mathrm{~m}$ in thickness. Volcanically derived arkosic sands and conglomerates, of subaerial origin, lie conformably above the Artesia units in many areas of the range. The sediments display graded bedding, confirming stratigraphic inferences and aiding in structural interpretations. Total sediment horizons reach $30 \mathrm{~m}$ in thickness and often two or more sediment sequences are intercalated with silicic volcanics (Fig. 1) which represent the lowermost part of the Fulstone Formation. Over $90 \%$ of this unit is a porphyritic flow or pyroclastic, which may be divided into lower plagioclase-amphibole and upper plagioclase-potassium feldspar-rich material.

The Fulstone and Artesia Formations are generally moderately altered, containing an ubiquitos chloritealbite \pm epidote-piedmontite mineral assemblage indicative of greenschist metamorphic conditions and/or deuteric alteration. Evidence from the textural relationships of the opaque phases (see discussion below) suggests that the phases formed by deuteric alteration soon after the emplacement of the volcanics. Excluding the uppermost pyroclastics of the Fulstone Formation, little, if any, of the original mafic magmatic 
mineralogy remains, and the presence of former amphibole and biotite phenocrysts is inferred on the basis of grain shapes and alteration products. The magnetic mineralogy of these units, as it relates to this pervasive alteration, will be described in a later section. Several small quartz-monzonite porphyry bodies cut the Artesia and Lower Fulstone units and probably represent feeders to overlying flows. The stocks, generally less altered than their hosts, are similar to quartz-monzonite porphyry dikes cutting intrusive units elsewhere in the district.

\section{Sampling and paleomagnetic methodology}

Sampling of Fulstone and Artesia units is distributed throughout the Buckskin Range; we will discuss the results from only one, heavily sampled fault block in the central portion of the range (Fig. 1), selected for its good exposures. Lack of water, inaccessibility and unusually tough materials precluded field drilling, so hand samples were collected at all sites using a magnetic compass for orientation. The intensities of natural remanent magnetization (NRM) are too low to expect magnetic orientation errors from ground anomalies.

Each site but one consisted of a single outcrop or a series of outcrops within $30 \mathrm{~m}$ of each other. Site 230 is a near-continuous exposure of Artesia and Fulstone units, about $270 \mathrm{~m}$ long, from which 53 samples were collected, after exposures were created by bulldozing. Site 230 is divided into five data groups (Table 1). The total number of sites for which data are compared is 17 (90 independently oriented samples). At least two specimens from each sample were measured and demagnetized. Site statistics were determined from the specimen data from the accepted samples (Table 1), as the within-sample dispersion is generally as great or greater than the between-sample dispersion.

Measurements of the magnetization were made using either a Schonstedt SSM1-A spinner magnetometer or an SCT cryogenic magnetometer. Behavior on demagnetization treatment was in all cases analyzed by vector diagrams [19]. Initial pilot alternating field (AF) demagnetization of Artesia and Fulstone samples revealed very high coercivities, with median demagnetizing fields generally greater than $100 \mathrm{mT}$.
Often the remanence had decreased by less than 5\% at this value. Pilot thermal demagnetization used either a Schonstedt thermal demagnetizer or a non-inductively wound furnace placed in a field-free space provided by a Helmholtz coil and Schonstedt HCM-3 triaxial controlled magnetometer feedback system (capable of maintaining a field of 5-10 nT or less). It indicated that the unblocking temperatures of the characteristic magnetization components were above $600^{\circ} \mathrm{C}$ (Fig. 2). The standard response at temperatures greater than $650^{\circ} \mathrm{C}$ was an univectorial decay of the magnetization to the origin. Subsequently, most samples, volcanics as well as volcanoclastics, were thermally demagnetized. In these treatments, usually one or two heatings were carried out at temperatures less than $580^{\circ} \mathrm{C}$, to determine and remove any magnetization components possibly residing in magnetite, followed by at least three heatings between temperatures of 620 and $680^{\circ} \mathrm{C}$. As either univectorial or totally non-systematic (rejected) behavior of the magnetization was generally exhibited by specimens over this temperature range, characteristic directions in the former case are chosen by vector analysis, using a linear segment of the demagnetization path. Samples from sites 39 and 43 possessed much lower coercivities and consequently $\mathrm{AF}$ as well as thermal demagnetization (only to $600^{\circ} \mathrm{C}$ ) were used to resolve the magnetization components.

Isothermal remanence magnetization (IRM) acquisition curves were determined using an electromagnet with a $20-\mathrm{cm}$-diameter pole piece, $4.3-\mathrm{cm}$ gap and a peak field of $1.27 \mathrm{~T}$. Hysteresis parameters were measured at the University of Toronto Rock Magnetism Laboratory, Erindale College.

\section{Paleomagnetic data}

\subsection{Characteristics magnetizations}

Magnetization data from all sites are listed in Table 1 and shown in Fig. 3. In-situ characteristic directions, within statistical limits, fall into two roughly antipodal groups with shallow inclinations and southwest to west or northeast to east declinations. We refer to the northeast group of directions as being of normal polarity, and to the southwest group as being 


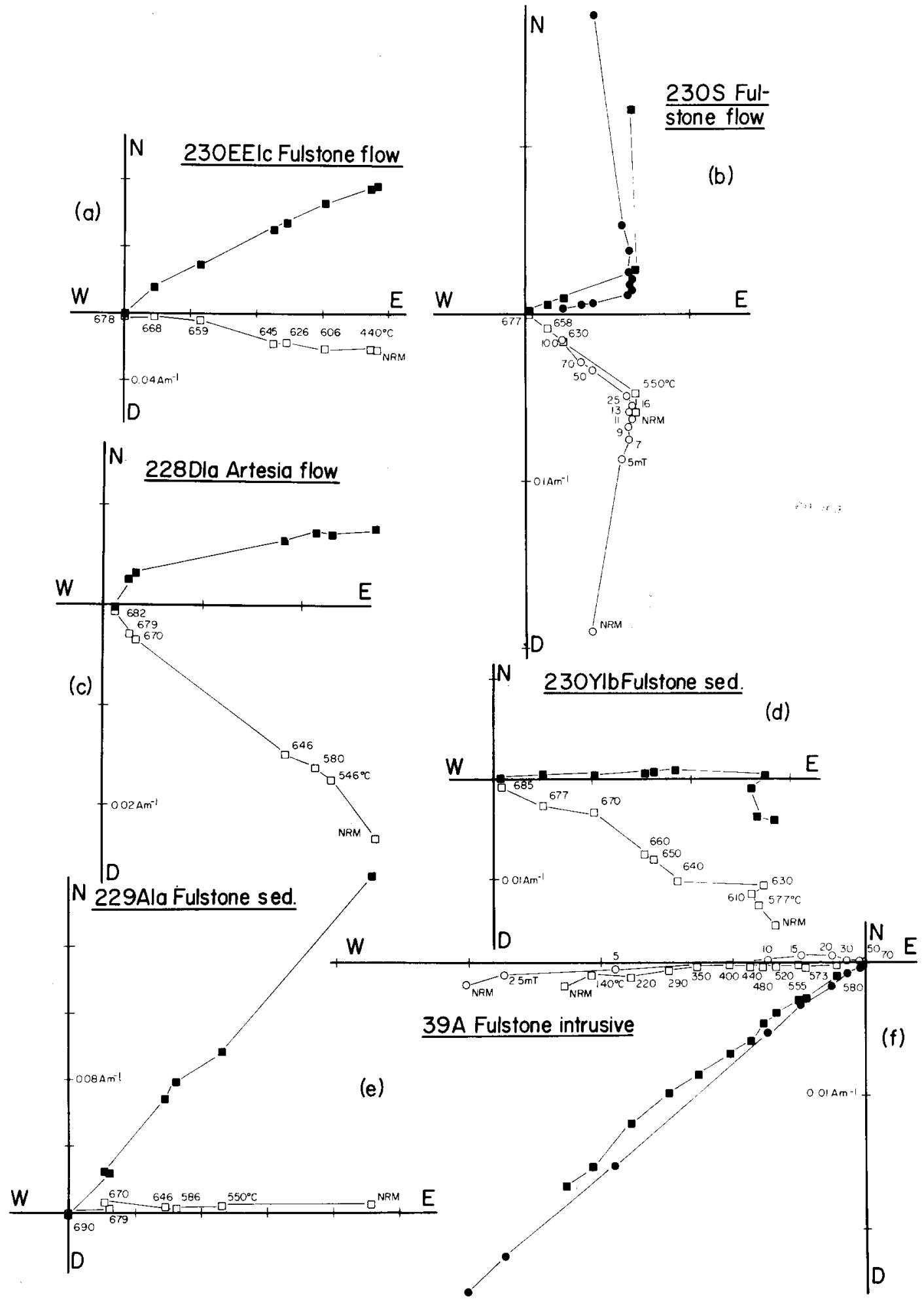

Fig. 2. (a)-(f). Orthogonal demagnetization diagrams of the end-point of the magnetization vector of specimens of the sampled units during progressive AF or thermal demagnetization. Solid (open) symbols denote projections of the magnetization vector onto the horizontal (vertical) plane. Axes always refer to field coordinates. Peak alternating fields, in $\mathrm{mT}$, or temperatures, in degrees Celsius, are indicated beside the projection on the vertical plane. 
TABLE 1

Magnetization data from Artesia and Fulstone units in the central Buckskin Range

\begin{tabular}{|c|c|c|c|c|c|c|c|c|c|}
\hline \multirow[t]{2}{*}{ Site } & \multirow[t]{2}{*}{ Lithology } & \multirow[t]{2}{*}{$N / N_{0}{ }^{a}$} & \multirow[t]{2}{*}{$n^{\mathrm{b}}$} & \multirow[t]{2}{*}{$J_{0} \mathrm{c}$} & \multicolumn{2}{|c|}{ Characteristic $^{\mathrm{d}}$} & \multirow[t]{2}{*}{$\alpha_{95} \mathrm{e}$} & \multirow[t]{2}{*}{$k^{\mathbf{f}}$} & \multirow[t]{2}{*}{ Polarity $g$} \\
\hline & & & & & decl. & incl. & & & \\
\hline 36 & Fulstone volcanics & $1 / 1$ & 4 & 49.3 & 334.0 & 68.4 & 10.0 & 85.3 & I \\
\hline 37 & Fulstone volcanics & $2 / 2$ & 8 & 310 & 209.5 & 0.2 & 6.8 & 67.0 & $\mathbf{R}$ \\
\hline 39 & Fulstone intrusive & $3 / 3$ & 8 & 19.0 & 234.6 & 10.0 & 15.2 & 14.2 & $\mathbf{R}$ \\
\hline 40 & Fulstone volcanics & $1 / 2$ & 3 & 840 & 91.6 & 3.3 & 4.9 & 621.9 & $\mathrm{~N}$ \\
\hline 43 & Fulstone intrusive & $2 / 2$ & 8 & 106 & 67.9 & -33.8 & 13.0 & 19.1 & $\mathbf{N}$ \\
\hline 44 & Fulstone volcanics & $3 / 3$ & 13 & 203 & 72.0 & 1.0 & 9.2 & 21.3 & $\mathbf{N}$ \\
\hline $44 \mathrm{~A}$ & Artesia & $2 / 2$ & 6 & 33.6 & 226.1 & -29.4 & 9.9 & 46.2 & $\mathbf{R}$ \\
\hline 228 & Artesia & $4 / 5$ & 10 & 52.6 & 253.7 & -6.4 & 20.0 & 8.6 & M \\
\hline \multirow[t]{2}{*}{229} & Fulstone sediments, & & & & & & & & \\
\hline & lower & $5 / 6$ & 17 & 29.8 & 220.3 & -11.5 & 12.8 & 8.6 & $\mathbf{R}$ \\
\hline 17 & $\begin{array}{l}\text { Fulstone sediments, } \\
\text { lower }\end{array}$ & $3 / 3$ & 10 & 85 & 2594 & -09 & 115 & & \\
\hline $230(\mathrm{~L})$ & Artesia & $7 / 8$ & 16 & 117 & 244.8 & -8.3 & $\begin{array}{r}11.5 \\
5.9\end{array}$ & $\begin{array}{l}18.6 \\
38.9\end{array}$ & $\begin{array}{l}\mathbf{M} \\
\mathbf{R}\end{array}$ \\
\hline \multirow[t]{3}{*}{$230(\mathrm{M})$} & Fulstone sediments, & & & & & & & & \\
\hline & lower & $14 / 16$ & 36 & 9.4 & 236.7 & -9.6 & 7.9 & 10.0 & $\mathbf{R}$ \\
\hline & upper & $5 / 5$ & 10 & 44.2 & 85.1 & 13.6 & 21.4 & 6.0 & $\mathbf{M}$ \\
\hline \multirow[t]{3}{*}{$230(\mathrm{U})$} & Fulstone volcanics, & & & & & & & & \\
\hline & lower & $4 / 4$ & 10 & 161 & 85.5 & 32.7 & 7.5 & 42.3 & $\mathbf{N}$ \\
\hline & upper & $20 / 20$ & 50 & 497 & 75.9 & 7.9 & 5.6 & 13.9 & $\mathbf{N}$ \\
\hline 231 & Fulstone volcanics & $5 / 5$ & 14 & 633 & 86.2 & -1.4 & 9.3 & 19.3 & $\mathbf{N}$ \\
\hline 235 & Fulstone volcanics & $3 / 3$ & 6 & 110 & 78.5 & 32.5 & 25.0 & 7.9 & $\mathbf{N}$ \\
\hline
\end{tabular}

a Ratio of samples accepted to total samples measured.

b Number of specimens, from $N$ samples, used for statistical purposes.

c Intensity of natural remanent magnetization $\left(\times 10^{-2} \mathrm{~A} / \mathrm{m}\right)$.

d Mean direction of remanence resolved in demagnetization, in degrees.

e Semi-angle of the cone of $95 \%$ confidence about the mean direction, in degrees.

f Fisher precision parameter.

g Polarity of characteristic remanence; $N=$ normal, $R=$ reversed, $M=$ mixed, $I=$ intermediate.

of reversed polarity, since approximate corrections for the tilt of the strata (with steep westerly dips) bring these directions close to those expected for Jurassic time.

Data from the Artesia volcanics at the base of the site 230 traverse are all of reversed polarity and yield a well-grouped mean direction $\left(\alpha_{95}=5.9^{\circ}\right)$, similar to those of the immediately overlying lower volcanoclastic sediments. Directions from some sediment samples, however, are of anomalous, steep inclination and these fluctuations may be primary in nature. The lower Fulstone volcanics interstratified arkosic sediments and the thick sequence of overlying Fulstone volcanics display approximately opposite (normal) polarity magnetization directions to those in the Artesia flows and basal Fulstone sediments. The mean direction from the basal Fulstone volcanics is statistically distinct from that of the flows above the upper sediments (see Fig. 3).

The same polarity sequence, with but few exceptions, is shown by the remaining sites. Sites 40,44 , 231 and 235, in Fulstone volcanics, have normal polarity characteristic directions. Sites 36 and 37 also in Fulstone volcanics, display anomalous and reverse polarity directions respectively. Intrusives within the Fulstone units, at sites 39 and 43, display reverse and normal polarity directions, respectively. Sites $44 \mathrm{~A}$ and 228 in andesites of the Artesia formation and 17 and 229 in basal Fulstone sediments, possess predominantly reverse polarity directions. 


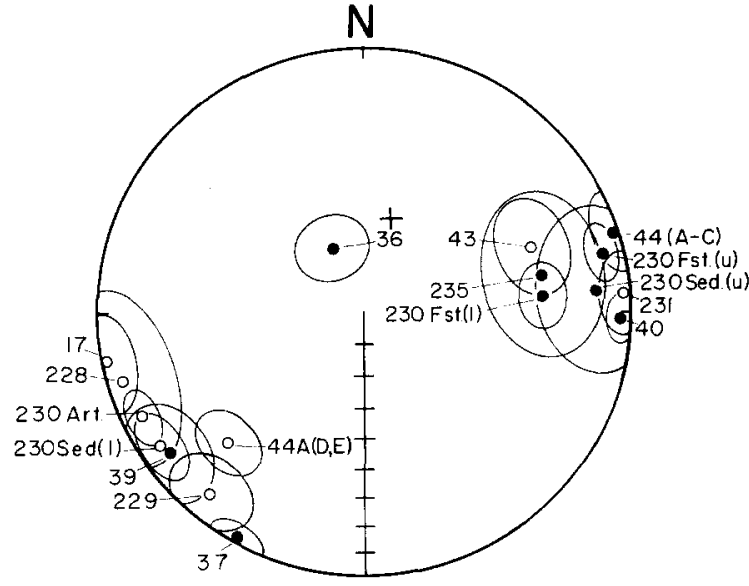

Fig. 3. Equal area projection of site mean directions and associated cones of $95 \%$ confidence for the 17 sites listed in Table 1. Open (solid) symbols refer to projections on the upper (lower) hemisphere. The cross is the present-day field direction.

\subsection{Demagnetization behavior}

In detail, response during demagnetization of the Fulstone and Artesia lithologies is by no means uniform, which aids - together with the stratigraphic variation in characteristic directions - in understanding the origin of the remanence in these units. The most typical response in thermal demagnetization, exhibited by the Artesia volcanics, the Fulstone volcanoclastic sediments and the majority of the Fulstone volcanics is a univectorial decay of a remanence of very high blocking temperature, removed only at temperatures well in excess of $600^{\circ} \mathrm{C}$ (Fig. 2a, c, d, e). Secondary components of magnetization are rare in these units. If present, they are removed in AF demagnetization in fields less the $25 \mathrm{mT}$ (e.g. Fig. $2 b)$, suggesting that they may reside in magnetite. In all samples of the intrusives at sites 39 and 43, however, blocking temperatures of the characteristic remanence are entirely below $580^{\circ} \mathrm{C}$ and in most cases both $\mathrm{AF}$ and thermal demagnetization serve to adequately illustrate a univectorial decay to the origin. In some instances, e.g. sample 39A (Fig. 2f), AF demagnetization reveals two slightly different components of magnetization, whereas thermal demagnetization resolves only one. In this example, the component removed between 15 and $70 \mathrm{mT}$, of shallow negative inclination, is taken to be the characteristic one.

\subsection{Magnetic mineralogy and rock magnetism}

Response to thermal and AF demagnetization by the Fulstone and Artesia volcanics and the Fulstone sediments indicates that hematite is the dominant carrier of the remanence. This observation is confirmed by microscopic examination and rock magnetic properties of the magnetic mineralogy. Hematite in the volcanics occurs predominantly as specularite, assuming several textural forms: as replacements of originally coarse titaniferous magnetite phenocrysts (Fig. 4a, b) as replacements of groundmass magnetite grains, as partial replacements of biotite or amphibole phenocrysts (Fig. 4c), as an introduced, exotic phase filling cracks or other voids within the rocks and, together with limonite, as irregular clouds of very fine submicroscopic, translucent particles within the groundmass of the flows. Migration of titanium from original magnetite is suggested by the common occurrence of secondary sphere and/or rutile near specularite grains.

Hysteresis parameters are given in Table 2. In comparison to values reported by Dunlop [20] for unannealed and annealed synthetic hematite powders of maximum dimensions less than $6 \mu \mathrm{m}$, coercivity $\left(H_{\mathrm{c}}\right)$ and coercivity of remanence $\left(H_{\mathrm{cr}}\right)$ values for the Yerington materials are significantly smaller while $H_{\mathrm{cr}} / H_{\mathrm{c}}$ values are nearly identical. The smaller values of $H_{\mathrm{c}}$ and $H_{\mathrm{cr}}$ confirm petrographic observations that the Fulstone units contain both single-domain and multidomain hematite, assuming a $20-$ to $76-\mu \mathrm{m}$ range for the single-domain to multidomain transition in hematite [21]. A few samples (e.g. 228H, Table 2) possess anomalously low $H_{\mathrm{c}}$ and $H_{\mathrm{cr}}$ values, but because their blocking temperatures are above $580^{\circ} \mathrm{C}$, we believe that their remanence resides in hematite. Assuming a value of $2000 \mathrm{~A} / \mathrm{m}(2.00 \mathrm{emu} /$ $\mathrm{cm}^{3}$ ) for the weak ferromagnetic saturation magnetization $\left(J_{\mathrm{s}}\right)$ of pure hematite [20], most $J_{\mathrm{s}}$ values in Table 2 correspond to volume percent hematite between about $13.0 \%$ and $5.0 \%$, in good agreement with petrographic observations. Initial susceptibility values further indicate a hematite-dominated remanence $[20,22]$.

Isothermal remanent magnetization (IRM) acqui- 

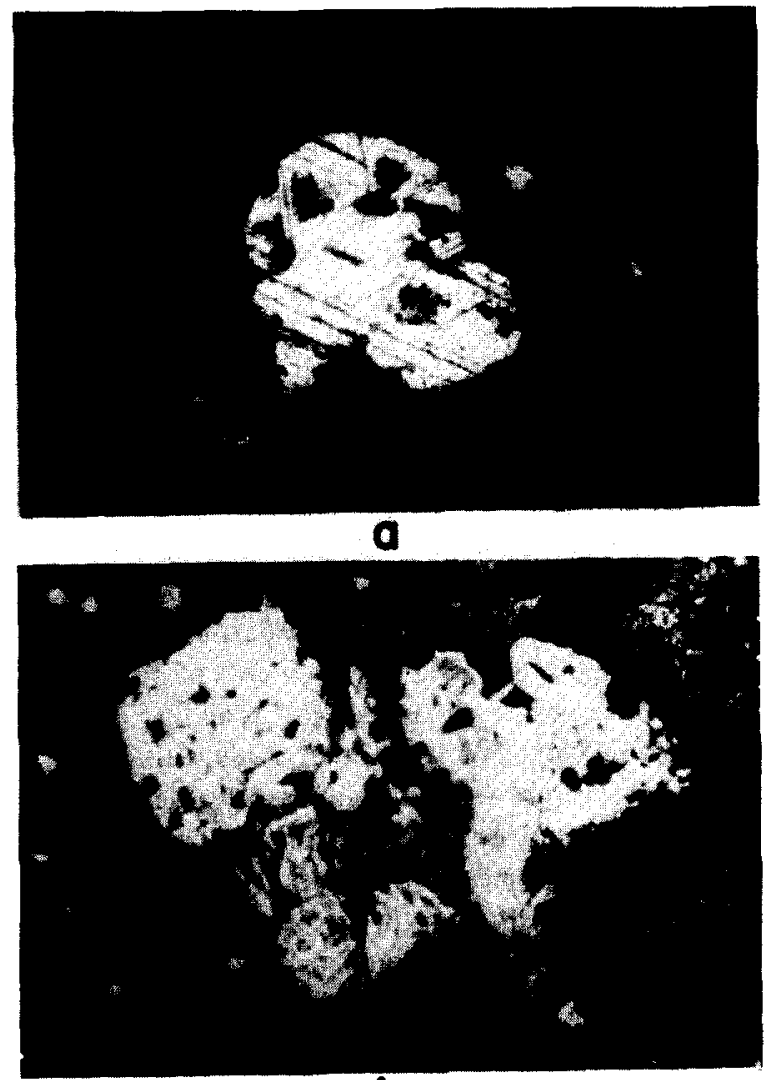

b

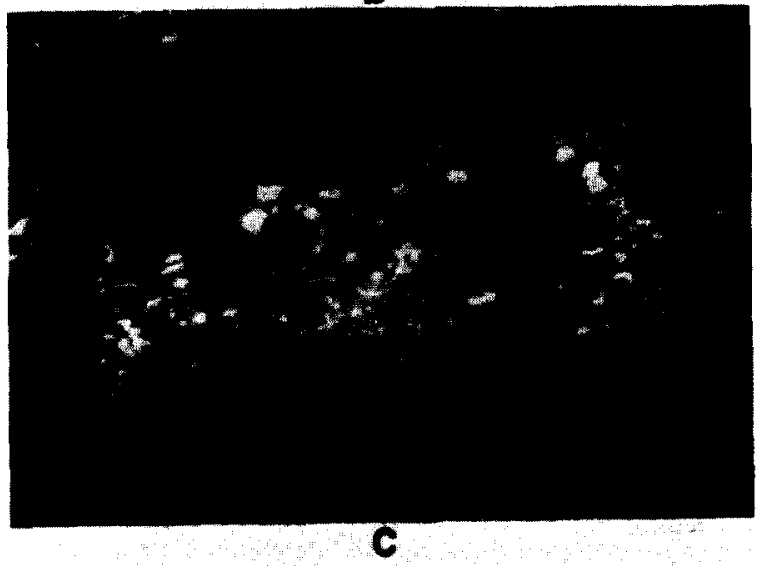

Fig. 4. Photomicrographs of typical hematite parageneses in the Fulstone and Artesia flow units. The scale bar in each photo is $50 \mu \mathrm{m}$. (a) Titaniferous magnetite phenocryst, originally with ilmenite lamellae, completely replaced by hematite, sample 230DDD, Artesia flow. (b) Magnetite and ilmenite grains replaced by hematite and hematite-rutileilmenite, respectively; note abundant groundmass hematite, sample 231B, Fulstone flow. (c) Amphibole phenocryst partially replaced by hematite; note abundant groundmass hematite, sample 44A, Fulstone flow. sition and backfield IRM demagnetization [23] tests, in which a saturation IRM is progressively demagnetized in a reversed DC field, were conducted on representative lithologies. A typical example for a sample of a Fulstone flow is shown in Fig. 5. Most importantly, the acquisition curves indicate that hematite is the dominant magnetic phase in the volcanic units, and the backfield demagnetization curves, yielding remanent coercive force values, support the premise that no magnetite remains in most of the Fulstone flows.

Interestingly, several backfield demagnetization curves display a rather abrupt change in slope at about $120-130 \mathrm{mT}$. Thus, at least two different classes of hematite mineralogies are present; one has remanent coercive forces of about $120-230 \mathrm{mT}$, the other values in excess of $500 \mathrm{mT}$. We suggest that the lower remanent coercive force value may be attributed to multidomain hematite grains replacing coarse titaniferous magnetite phenocrysts and the higher values to groundmass hematite. IRM acquisition and backfield demagnetization tests on the intrusives as sites 39 and 43 further support the existence of magnetite as the essential magnetic phase present in these units.

\section{Discussion}

We contend that the hematite-dominated remanence of the Fulstone and Artesia volcanics is the result of thorough deuteric oxidation essentially penecontemporaneous with emplacement. Oxidation was not in conjunction with a thermal overprinting of the entire terrane in post-Middle Jurassic time nor primary igneous precipitation of hematite in the original equilibration and emplacement of the silicate melt. The essential lines of evidence for this conclusion are the distribution of normal and reverse polarity characteristic magnetization directions between investigated lithologies and the correlation of hematite-dominated remanences with subareal units and non-oxidized magnetite-dominated remanences with contemporaneous cross-cutting intrusive units. In addition, temperature-oxygen fugacity conditions known for silicate magmas preclude equilibrium precipitation of hematite, instead of magnetite, as the iron oxide phase in silicic to intermediate volcanics 
TABLE 2

Hysteresis properties of Artesia and Fulstone units

\begin{tabular}{|c|c|c|c|c|c|c|}
\hline Sample & $J_{\mathbf{s}}{ }^{\mathbf{a}}$ & $J_{\mathrm{r}}^{\mathrm{b}}$ & $J_{\mathbf{r}} / J_{\mathbf{S}}$ & $H_{\mathrm{c}} \mathrm{c}$ & $H_{\mathrm{cr}} \mathrm{d}$ & $x_{i}{ }^{e}$ \\
\hline $39 \mathrm{~B}$ & 0.274 & 0.029 & 0.1083 & 25.0 & 75.0 & 0.00127 \\
\hline $40 \mathrm{C}$ & 0.144 & 0.030 & 0.183 & 95.0 & 450.0 & 0.00039 \\
\hline $43 B$ & 0.085 & 0.032 & 0.4025 & 80.0 & 300.0 & 0.00029 \\
\hline $228 \mathrm{E}$ & 0.481 & 0.091 & 0.1895 & 120.0 & 160.0 & 0.00048 \\
\hline $228 \mathrm{H}$ & 0.554 & 0.003 & 0.0059 & 16.0 & 95.0 & 0.00004 \\
\hline $230 \mathrm{Q}$ & 0.138 & 0.058 & 0.444 & 350.0 & 1400.0 & 0.00007 \\
\hline $230 \mathrm{Z}$ & 0.176 & 0.016 & 0.0929 & 142.0 & 350.0 & 0.00014 \\
\hline $230 \mathrm{BB}$ & 0.398 & 0.023 & 0.0583 & 70.0 & 280.0 & 0.00044 \\
\hline 230TT & 0.290 & 0.030 & 0.1050 & 72.0 & 205.0 & 0.00049 \\
\hline 230UU & 0.220 & 0.025 & 0.1149 & 122.0 & 260.0 & 0.00013 \\
\hline $230 \mathrm{VV}$ & 0.214 & 0.032 & 0.148 & 82.0 & 240.0 & 0.00037 \\
\hline $231 \mathrm{~A}$ & 0.275 & 0.048 & 0.1746 & 170.0 & 500.0 & 0.00022 \\
\hline 231C & 0.279 & 0.033 & 0.118 & 110.0 & 230.0 & 0.00029 \\
\hline
\end{tabular}

a Saturation magnetization $\left(10^{3} \mathrm{~A} / \mathrm{m}\right)$.

$b^{b}$ Saturation remanence $\left(10^{3} \mathrm{~A} / \mathrm{m}\right)$.

c Coercive force, in $\mathrm{mT}$, determined by whole-rock hysteresis tests.

d Coercivity of remanence, in $\mathrm{mT}$, determined by extrapolation in whole-rock hysteresis tests.

e Initial susceptibility.

$[2,4,24]$. Deuteric oxidation of the Artesia and Fulstone volcanics may have occurred relatively quickly on a local scale but it may have spanned several thousands of years within one or more flow units. Thus, the recording of opposite polarity, anomalous, or statistically distinct (but still constant polarity) directions over limited stratigraphic intervals between indistinguishable flow units or within identical flow units is possible. We therefore interpret the general progression from reversed polarity lithologies in the eastern (older) part of the sampling area to normal polarity lithologies in the western (younger) part as representing a change in the Jurassic field from pre-

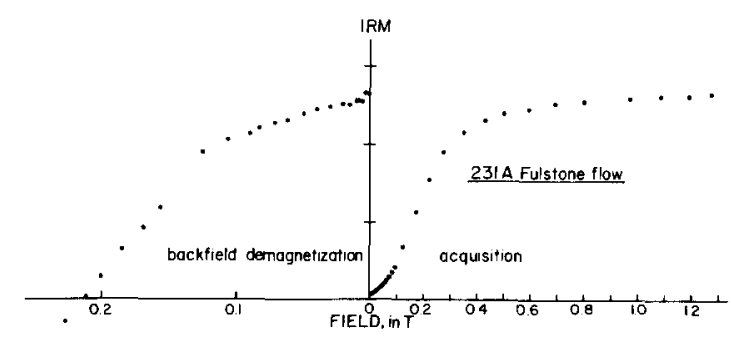

Fig. 5. IRM acquisition and backfield demagnetization of IRM curves for a sample of a Fulstone flow at site 231. The dots are experimental points. dominantly reversed to predominantly normal polarity.

By virtue of the mechanism we propose, the hematite-dominated remanence in the volcanics is either a TRM, a TCRM or a combination of both, and the formation of this remanence is schematically shown in Fig. 6. If all the replacing hematite was formed at temperatures in excess of hematite's Néel temperature, $675-690^{\circ} \mathrm{C}[20,25]$, a TRM would be acquired in subsequent cooling. Alternatively, if the replacement process occurred at temperatures lower than the Néel temperature, the remanence would be a TCRM. The temperature-oxygen fugacity path followed by the volcanics upon extrusion will dictate the type of magnetization acquired by hematite. The larger first-order effect in extrusion is probably oneof cooling rather than a rapid increase in oxygen fugacity $[6,11]$ and the hematite-magnetite buffer might be intersected at temperatures near $600^{\circ} \mathrm{C}$. If intersection of the buffer curve occurred at significantly higher temperatures, the hematite remanence in the Fulstone and Artesia units would be a combination of a TRM and a TCRM. While we cannot be certain which remanence predominates, oxidation did occur at relatively high temperatures because maghemite, commonly formed by low-temperature 


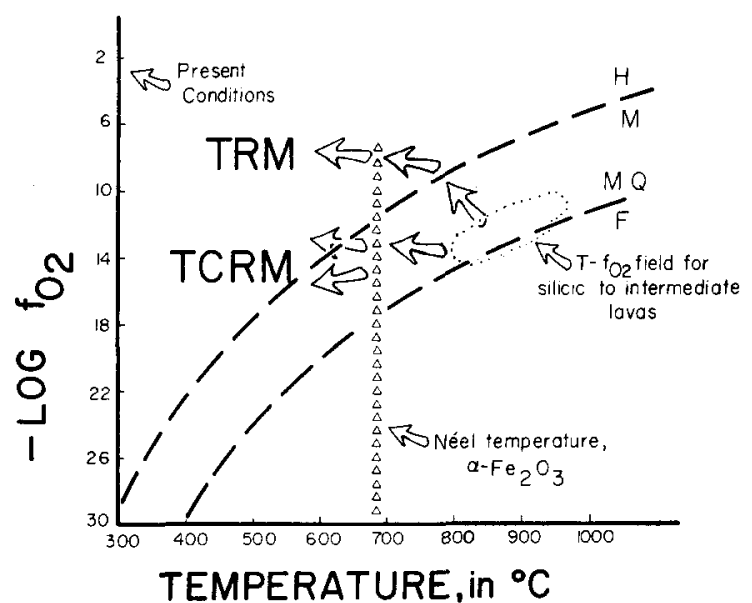

Fig. 6. Inferred initial $T-f_{\mathrm{O}_{2}}$ regime for Artesia and Fulstone flows (dotted area) and possible $T-f_{\mathrm{O}_{2}}$ paths for the acquisition of TRM or TCRM remanences. The dashed lines represent the hematite $(H)$-magnetite $(M)$ and magnetite $(M)-$ fayalite (F)-quartz (Q) buffers. The location of both paths is only schematic; the paths are meant to emphasize that if hematite forms above its Néel temperature it will acquire a TRM, whereas if it forms from magnetite below the Néel or Curie temperatures, a TCRM will be acquired.

$\left(150-200^{\circ} \mathrm{C}\right)$ oxidation of magnetite [1] and predicted to be thermodynamically unstable at temperatures in excess of $350^{\circ} \mathrm{C}$ [26] was not detected optically nor magnetically (by thermal demagnetization and thermomagnetic analysis) in any of the units examined.

Theoretical modelling of the acquisition of a hematite-dominated remanence in the Fulstone and Artesia flows is difficult solely on the basis of the magnetic properties and magnetic mineralogies of the units. The remanence is possibly a combination of a TRM and a CRM, and while Stacey and Banerjee [1] suggest the comparable magnitudes of TRM and CRM for hematite, their calculations assume simple, single-domain models. NRM intensities of the Fulstone and Artesia volcanics, between about 6.3 and $0.3 \mathrm{~A} / \mathrm{m}$, approximate those from extrapolation of Dunlop's [20] TRM experiments on synthetic hematite powders of $0.2-1 \mu \mathrm{m}$ grain sizes subjected to a field of $0.05 \mathrm{mT}$. Alternatively, Stacey [22] suggested that a room-temperature CRM carried by single-domain hematite grown in a field of $0.05 \mathrm{mT}$ should be about $8.0 \times 10^{-3} \mathrm{~A} / \mathrm{m}$ per $1 \%$ hematite, substantially lower than the Fulstone and Artesia values. As hematite in the Fulstone and Artesia units grew at elevated temperatures, probably in excess of $600^{\circ} \mathrm{C}$, extrapolation of a CRM model is questionable. Temperatures significantly higher than room temperature may not have such a critical effect on the acquisition of a TRM. For one, coercivities of single-domain hematite particles, even at $650^{\circ} \mathrm{C}$, are on the order of 5.0-10.0 mT [20,27], sufficiently large values to ensure stability of a high-temperature CRM or a TRM in the earth's field. Discrete blocking temperature spectra of synthetic materials [20], similar to those of the Artesia and Fulstone flows, also suggest the stability of a high-temperature CRM.

A second complexity in the acquisition of the hematite remanence by the volcanics is that the hematite was precipitated from pre-existing magnetic minerals, and that the TCRM (or TRM) is even more complicated to treat [1]. The magnetostatic field exerted by the reactant magnetite on the product hematite and the exchange interactions across spinelrhombohedral phase boundaries are critical factors in the formation of a magnetic moment in the hematite [28]. Stacey and Banerjee [1] claim that the magnetization resulting from a chemical replacement may actually have a direction between that of the preexisting mineral and that of the ambient field. Hedley [29] and Merrill [30] discuss the relation of grain shape to exchange interactions in the analysis of the resulting CRM direction. It was thought that shape anisotropy in elongate single-domain grains would probably preclude perturbations of the original remanence [30-32], but Henshaw and Merrill [33] suggest that shape anisotropy does not usually pin the direction of remanence in a single-domain grain. For single-domain particles, positive exchange coupling between magnetite and replacing hematite would hold the initial remanence invariant during chemical changes, while a negative coupling [29] would yield a self-reversal of the original remanence. If multidomain structures are involved, neither shape anisotropy nor positive exchange interactions will suffice to preserve the original direction of TRM (held by magnetite) in the units. The fact that characteristic directions in the Fulstone and Artesia volcanics are parallel to those of intrusives whose remanence is dominated by primary magnetite indicates that the acquisition of a hematite remanence in turn accurately recorded the geomagnetic field. In addition, 
Johnson and Merrill [31] found that the CRM acquired in partial oxidation of pseudo-single-domain magnetite contained a remanence parallel to the applied field, not to the pre-existing direction in magnetite. On the other hand, complete low-temperature oxidation of single-domain magnetite failed to produce a magnetization (CRM) parallel to the applied field [34]. Johnson and Merrill's results on pseudo-single-domain magnetites imply that, if an original magnetite-dominated remanence was contained in the Fulstone and Artesia units, oxidation took place soon afterwards.

\section{Conclusions}

Extensive deuteric oxidation of the Fulstone and Artesia volcanics appears to have been an accurate and reliable magnetization recording process, even though the resulting magnetization may be of complex, high-temperature deuteric origin. The presence of antipodal magnetization directions in all lithologies, magnetizations in interbedded volcanoclastic sediments and arkoses appearing to be primary in character, and contrasting magnetic mineralogies in consanguineous volcanics and intrusives all imply that the remanence of the Fulstone and Artesia volcanics is not a result of a significantly later thermochemical event, i.e. regional metamorphism. High-temperature pervasive oxidation of rapidly chilled volcanic units such as the Fulstone and Artesia formations results in a remanence, though of unexpected character and behavior in demagnetization, that may be a more stable, accurate and hence reliable indicator of the geomagnetic field than a TRM acquired by predicted cubic phases. In the case of the Fulstone and Artesia flows, we believe that the hematite-dominated characteristic magnetization is perfectly valid as an indicator of their total, post-emplacement deformation.

\section{Acknowledgements}

We thank the General Mining Division of The Anaconda Company for their support and cooperation in this project. S.K. Banerjee and D.W. Strangway provided pre-submittal reviews. We also thank
R.T. Merrill and two anonymous reviewers for their helpful criticism. R.T. Merrill and P. Henshaw kindly provided a preprint of their work on marine sediments.

\section{References}

1 F.D. Stacey and S.K. Banerjee, The Physical Principles of Rock Magnetism (Elsevier, Amsterdam, 1974).

2 S.E. Haggerty, The aeromagnetic mineralogy of igneous rocks, Can. J. Earth Sci. 16 (1979) 1281.

3 D.J. Dunlop, TRM in submicroscopic magnetite, J. Geophys. Res. 78 (1973) 7602.

4 I.S.E. Carmichael and J. Nicholls, Iron-titanium oxides and oxygen fugacities in volcanic rocks, J. Geophys. Res. 72 (1967) 4665.

5 A.F. Buddington and D.H. Lindsley, Iron-titanium oxide minerals and their synthetic equivalents, J. Petrol. 5 (1964) 310.

6 R.F. Fudali, Oxygen fugacities of basaltic and andesitic magmas, Geochim. Cosmochim. Acta 29 (1963) 1063.

7 H.P. Eugster and D.R. Wones, Stability relations of the ferruginous biotite annite, J. Petrol. 3 (1962) 82.

8 D.R. Wones and M.C. Gilbert, The fayalite-magnetitequartz assemblage between 600 and $800^{\circ} \mathrm{C}$, Am. J. Sci. $267 \mathrm{~A}$ (1969) 480.

9 J.S. Haggerty, Opaque mineral oxides in terrestrial igneous rocks, in: Oxide Minerals, D. Rumble, III, ed. (Mineralogical Society of America, Washington, D.C., 1976).

10 C.S. Grommé, T.L. Wright and D.L. Peck, Magnetic properties and oxidation of iron-titanium oxide minerals in Alae and Makaopuhi lava lakes, Hawaii, J. Geophys. Res. 74 (1969) 5277.

11 J. Verhoogen, Distribution of titanium between silicates and oxides in igneous rocks, Am. J. Sci. 260 (1962) 211.

12 J.W. Geissman, R. Van der Voo and K.L. Howard, Jr., A paleomagnetic study of structural deformation in the Yerington district, Nevada, III. Mesozoic "basement" units and their total and pre-Oligocene tectonism (submitted to Am. J. Sci.).

13 J.M. Proffett, Jr., Report of the geology of the Yerington district, The Anaconda Company Geological Files (1969).

14 B.C. Burchfiel and G.A. Davis, Nature and controls of Cordilleran orogenesis, Western United States: extensions of an earlier synthesis, Am. J. Sci. 275A (1975) 363.

15 R.C. Speed, Paleogeographic and plate tectonic evolution of the Early Mesozoic marine province of the western Great Basin, in: Mesozoic Paleogeography of the Western United States, D.G. Howell and K.A. McDougall, eds. (Society of Economic Paleontologists and Mineralogists, Los Angeles, Calif., 1978) 253.

16 R.A. Schweickert, Triassic and Jurassic paleogeography of the Sierra Nevada and adjacent regions, California and Western Nevada, in: Mesozoic Paleogeography of the Western United States, D.G. Howell and K.A. McDougall, 
eds. (Society of Economic Paleontologists and Mineralogists, Los Angles, Calif., 1978) 361.

17 J.S. Oldow, Triassic Pamlico Formation; an allochthonous sequence of volcanogenic-carbonate rocks in west-central Nevada, in: Mesozoic Paleogeography of the Western United States, D.G. Howell and K.A. McDougall, eds. (Society of Economic Paleontologists and Mineralogists, Los Angeles, Calif., 1978) 223.

18 A. Knopf, Geology and ore deposits of the Yerington district, Nevada, U.S. Geol. Surv. Prof. Paper 114 (1918).

19 J.D.A. Zijderveld, A.C. demagnetization of rocks: analysis of results, in: Methods in Paleomagnetism, D.W. Collinson, K.M. Creer and S.K. Runcorn, eds. (Elsevier, Amsterdam, 1967) 254.

20 D.J. Dunlop, Magnetic properties of fine-particle hematite, Ann. Geophys. 27 (1971) 269.

21 R. Chevallier and S. Matthieu, Proprietés magnétiques des poudres d'hematites - influence des dimensions des grains, Ann. Phys. 18 (1943) 258.

22 F.D. Stacey, The physical theory of rock magnetism, Adv. Phys. 12 (1963) 45.

23 J.K. Park, Paleomagnetism of the Flin Flon-Snow Lake Greenstone Belt, Manitoba and Saskatchewan, Can. J. Earth Sci. 12 (1975) 1272.

24 M. Sato and T.L. Wright, Oxygen fugacities directly measured in magmatic gases, Science 153 (1966) 1103.

25 A. Aharoni, E.H. Frei and M. Schieber, Some properties of $\gamma-\mathrm{Fe}_{2} \mathrm{O}_{3}$ obtained by hydrogen reduction of $\alpha-\mathrm{Fe}_{2} \mathrm{O}_{3}$, J. Phys. Chem. Solids 23 (1962) 545.
26 J. Benard, Etude de la décomposition du protooxide de fer et de solutions solides, Ann. Chim. 12 (1939) 5.

27 M.M. Bina and M. Prevot, Hematite grains: size and coercive force from AF demagnetization at high temperatures, Phys. Earth Planet. Inter. 13 (1977) 272.

28 A.Y. Vlasov, G.V. Kovalenko and N.V. Fedoseeva, The rotational magnetic hysteresis of single hematite crystals in artificial sediments containing magnetite and hematite particles, Solid. Earth Phys. 2 (1967) 98.

29 I.G. Hedley, Chemical remanent magnetization of the $\mathrm{FeOOH}, \mathrm{Fe}_{2} \mathrm{O}_{3}$ system, Phys. Earth Planet. Inter. 1 (1968) 103.

30 R.T. Merrill, Magnetic effects associated with chemical changes in igneous rocks, Geophys. Surv. 2 (1975) 277.

31 H.P. Johnson and R.T. Merrill, Magnetic and mineralogical changes associated with low temperature oxidation of magnetite, J. Geophys. Res. 77 (1972) 334.

32 H.P. Johnson and R.T. Merrill, Low-temperature oxidation of a titanomagnetite and the implications for paleomagnetism, J. Geophys. Res. 78 (1973) 4938.

33 P. Henshaw and R.T. Merrill, Magnetic and chemical changes in marine sediments, Rev. Geophys. Space Phys. (in press).

34 H.P. Johnson and R.T. Merrill, Low-temperature oxidation of a single-domain magnetite, J. Geophys. Res. 79 (1974) 5533 . 